A recent prospective, observational study compared 1,252 ICU patients who received oral care with 414 historical controls who did not receive oral care [4]. The incidence rate of VAP was significantly lower in the oral care group than in the nonoral care group. The recent study of KOEMAN et al. [5] reported the results of a randomised, double-blind, placebo-controlled trial with three arms: chlorhexidine, chlorhexidine/colistin and placebo. Trial medication was applied every $6 \mathrm{~h}$ in the buccal cavity of the 385 included patients. The daily risk of VAP was reduced in both treatment groups compared with placebo, to $65 \%$ for chlorhexidine and $55 \%$ for chlorhexidine and colistin. Another prospective, randomised study evaluated the effect of oropharyngeal decontamination by povidoneiodine on VAP in 98 patients with head trauma [6]. The study found a significant reduction in the rate of VAP in the povidone-iodine group when compared with the saline and control groups. In addition, a recent meta-analysis assessed the efficacy of topical chlorhexidine for prevention of VAP [7]. Seven randomised controlled trials met the inclusion criteria. Topical chlorhexidine resulted in a reduced incidence of VAP and subgroup analysis showed that the benefit of chlorhexidine was most marked in cardiac surgery patients. Another recent meta-analysis evaluated the effect of oral decontamination on the incidence of VAP and mortality in mechanically ventilated adults [8]. Eleven trials totalling 3,242 patients met the inclusion criteria. Oral decontamination using antiseptics was associated with reduced risk of VAP. Neither antiseptic nor antibiotic oral decontamination reduced mortality or duration of mechanical ventilation.

Tracheotomy facilitates oral care compared with oral translaryngeal intubation. This may partly explain the lower ventilator-associated pneumonia rate that our study found in tracheotomised patients [9]. However, pathogenesis of ventilator-associated pneumonia is multifactorial and prevention of VAP should be based on measures reducing colonisation, aspiration and antimicrobial resistance. Although several simple interventions are useful for reducing ventilator-associated pneumonia rates, opportunities for decreasing these seem to be greatest when multi-module programmes are applied [10].

\section{S. Nseir}

Intensive Care Unit, Calmette Hospital, University Hospital of Lille, Lille, France.

\section{STATEMENT OF INTEREST}

None declared.

\section{REFERENCES}

1 Metheny NA, Clouse RE, Chang YH, Stewart BJ, Oliver DA, Kollef MH. Tracheobronchial aspiration of gastric contents in critically ill tube-fed patients: frequency, outcomes, and risk factors. Crit Care Med 2006; 34: 1007-1015.

2 Safdar N, Crnich CJ, Maki DG. The pathogenesis of ventilator-associated pneumonia: its relevance to developing effective strategies for prevention. Respir Care 2005; 50: 725-739.

3 Craven DE. Preventing ventilator-associated pneumonia in adults: sowing seeds of change. Chest 2006; 130: 251-260.

4 Mori H, Hirasawa H, Oda S, Shiga H, Matsuda K, Nakamura M. Oral care reduces incidence of ventilatorassociated pneumonia in ICU populations. Intensive Care Med 2006; 32: 230-236.

5 Koeman M, van der Ven AJ, Hak E, et al. Oral decontamination with chlorhexidine reduces the incidence of ventilator-associated pneumonia. Am J Respir Crit Care Med 2006; 173: 1348-1355.

6 Seguin P, Tanguy M, Laviolle B, Tirel O, Malledant Y. Effect of oropharyngeal decontamination by povidoneiodine on ventilator-associated pneumonia in patients with head trauma. Crit Care Med 2006; 34: 1514-1519.

7 Chlebicki MP, Safdar N. Topical chlorhexidine for prevention of ventilator-associated pneumonia: a meta-analysis. Crit Care Med 2007; 35: 595-602.

8 Chan EY, Ruest A, Meade MO, Cook DJ. Oral decontamination for prevention of pneumonia in mechanically ventilated adults: systematic review and meta-analysis. BMJ 2007; 334: 889.

9 Nseir S, Di Pompeo C, Jozefowicz E, et al. Relationship between tracheotomy and ventilator-associated pneumonia: a case-control study. Eur Respir J 2007; 30: 314-320.

10 Gastmeier P, Geffers C. Prevention of ventilator-associated pneumonia: analysis of studies published since 2004. J Hosp Infect 2007; 67: 1-8.

\title{
Need to prioritise: end-of-life decision-making in India
}

\section{To the Editors:}

I read with interest the recent article "End-of-life decisionmaking in respiratory intermediate care units: a European survey" by NAvA et al. [1], wherein the authors have beautifully covered the epidemiology, practice, behaviours and attitudes towards end-of-life decision-making in respiratory units in Europe. However, there are certain points regarding end-of-life decision-making in developing countries like India that merit attention.

First, Indian data on withdrawal of or withholding intensive care in terminally ill patients is sparse. Only two studies [2, 3] have been performed in five centres across the country with varied results. A unicentric survey on the practices of end-oflife decision-making in North India [2] noted that $78 \%$ of 
patients received full resuscitation; even in the $22 \%$ who were classified as receiving limitation of care, $18.8 \%$ were actually transferred out of the intensive care unit (ICU) terminally (left against medical advice) for financial or other reasons. Only $1.6 \%$ of ICU deaths had do-not-resuscitate orders and another $1.6 \%$ had withholding of life support [2]. A second study carried out at four centres in Mumbai [3] revealed that 34\% of deaths had limitation of therapy terminally. Approximately $25 \%$ of these patients were not intubated terminally; $67 \%$ were initially intubated and ventilated but failed to recover and, subsequently, had no further escalation of therapy; and $8 \%$ had withdrawal of therapy [3].

Secondly, apart from the educational, social and cultural differences, the healthcare system in India differs substantially from that in Europe. In Europe, government and national health insurance account for $70 \%$ of total health expenditure [4] compared with $20 \%$ in India, where $80 \%$ of the total healthcare bill is paid by the patient or their relatives [5].

Thirdly, the ethical and legal status of withholding and withdrawal of life-sustaining therapy from critically ill patients in India is ambiguous. Concepts like autonomy and death with dignity have not been explored in any meaningful way by the constitution. Euthanasia and physician-assisted suicide are not legal. Consequently, physicians are often reluctant to proactively limit therapy.

Fourthly, India has less than one hospital bed per 1,000 people and an even lower number of ICU beds [5].

Given the scarcity of resources and growing needs in India, it is the right time for physicians and allied healthcare societies to educate the government and public about the magnitude of the problem, and to start a healthy dialogue in order to reach a constitutional and legal directive with regard to withholding and withdrawal of care in critically ill patients.

\section{A. Singh}

Christian Medical College and Hospital, Ludhiana, India.

\section{STATEMENT OF INTEREST}

None declared.

\section{REFERENCES}

1 Nava S, Sturani C, Hartl S, et al. End-of-life decision-making in respiratory intermediate care units: a European survey. Eur Respir J 2007; 30: 156-164.

2 Mani RK. Limitation of life support in the ICU. Ethical issues relating to end of life care. Indian J Crit Care Med 2003; 7: 112-117.

3 Kapadia F, Singh M, Divatia J, et al. Limitation and withdrawal of intensive therapy at the end of life: practices in intensive care units in Mumbai, India. Crit Care Med 2005; 33: $1272-1275$.

4 World Health Organization. The World Health Report 2002: reducing risks, promoting healthy life. Geneva, World Health Organization, 2002.

5 Ministry of External Affairs, Government of India. Healthcare. http:/ / meaindia.nic.in/indiapublication/healthcare.htm. Date created: June 19, 2004. Date last accessed: July 8, 2007.

DOI: $10.1183 / 09031936.00085707$

\section{Cardiovascular and metabolic effects of CPAP in obese obstructive sleep apnoea patients}

\section{To the Editors:}

In a recent issue of the European Respiratory Journal, CoUGHLIN et al. [1] demonstrated that, in Caucasians with untreated obstructive sleep apnoea (OSA), continuous positive airway pressure (CPAP) can improve baroreceptor responsiveness and reduce waking blood pressure within 6 weeks, but that this treatment period was insufficient to modify insulin resistance or change the metabolic profile. This is the first randomised placebo-controlled blinded crossover trial comparing cardiovascular and metabolic outcomes after 6 weeks of therapeutic and sham CPAP in obese symptomatic Caucasians with OSA. We have found similar CPAP effects in obese Japanese OSA patients (table 1). The authors suggested that there is a need to offer multiple modalities of treatment to obese OSA patients if their cardiovascular risk profile is to be successfully modified. We totally agree with their conclusion. However, it may be necessary to address the following unresolved issues.

1) Although the participating OSA subjects were randomised to receive either therapeutic or identical sham CPAP, sham
CPAP may not be the best placebo treatment. Although therapeutic CPAP improves sleep quality in OSA patients, sham CPAP may not always improve sleep quality and daytime function in patients [2]. Healthy individuals without OSA may experience night-time CPAP as a form of torture. However, patients with severe OSA have a good night's sleep with CPAP.

2) The severity of the OSA may influence the effect of CPAP on metabolic outcomes. As shown in table 1, CPAP treatment exerted significant effects on some metabolic variables in very severe OSA (apnoea/hypopnoea index (AHI) $>45$ events $\cdot h^{-1}$ ), but not in moderate-to-severe OSA (AHI $<45$ events $\cdot h^{-1}$ ).

3) There is an effect of sex on metabolic outcomes and sleep apnoeas [3]. Risk factors for metabolic syndrome also differed by sex; in males, age, body mass index (BMI) and OSA (AHI $\geqslant 15$ events $\cdot h^{-1}$ ) were significantly associated with metabolic syndrome, whereas in females, BMI was the only risk factor [4].

4) The effect of short-term withdrawal of CPAP therapy on cardiovascular and metabolic variables may be of interest in 